\title{
Performance e Feminismos: diálogos para habitar o corpo-encruzilhada
}

Performance and Feminisms: dialogues to inhabit the crossroad-body

Camila Bastos Bacellar ${ }^{1}$ 


\section{Resumo}

As performances Merci Beaucoup, Blanco! de Michelle Mattiuzzi, gordura trans \#3 /gordura localizada \#1 de Miro Spinelli e Solange, tô aberta! de Pêdra Costa abrem a possibilidade de pensarmos que tais artistas articulam seus modos de existência com processos de criação desestabilizando um sistema de mundo no qual a opressão de gênero é racializada e oriunda de uma lógica colonial, capitalista e heterosexista. Esse texto busca se aproximar das intensidades destes trabalhos artísticos em que 0 corpo é o campo de batalha e o artefato vivo para estabelecer um diálogo entre estas intensidades - desde onde elas me tocam - e teorias feministas interseccionais, descoloniais e transfeministas.

Palavras-chave: corpo; performance; feminismos; interseccionalidade

\section{Abstract}

The performances Merci Beaucoup, Blanco! from Michelle Mattiuzzi, gordura trans \#3 /gordura localizada \#1 from Miro Spinelli e Solange, tô aberta! from Pêdra Costa open up the possibility to think that these artists articulate their modes of existence with creative processes disrupting a world system in which gender oppression is racialized and arises from a logic that is colonial, capitalistic and heterosexist. This text aims to get close to the intensity of this artistic works in which the body is the batlle field and the live artifact to establish a dialogue between this intensities - from where the affect me - and feminist theories such as interseccional, decolonial and transfeminist theories.

Keywords: body; performance; feminisms; interseccionality 
Esse texto busca se aproximar das intensidades de trabalhos artísticos em que o corpo é o campo de batalha, o artefato vivo, a fronteira onde se negocia visibilidade e invisibilidade para estabelecer um diálogo entre estas intensidades - e desde onde elas me tocam - e teorias feministas interseccionais, descoloniais e transfeministas. Seguindo pistas de teóricas como Amelia Jones e Eleonora Fabião, buscarei relacionar as performances de Michelle Mattiuzzi, Miro Spinelli e Pêdra Costa a "efeitos e afetos feministas" (Fabião, 2014, p.29). A motivação para pensar as relações entre performance e o campo crítico dos feminismos veio pela percepção, recorrente em minha pesquisa de doutorado ainda em andamento, da escassez de material que trate dos diálogos com efeitos e afetos feministas no trabalho com performance no Brasil. As performances Merci Beaucoup, Blanco! de Michelle Mattiuzzi, gordura trans \#3 Igordura localizada \#1 de Miro Spinelli e Solange, tô aberta! de Pêdra Costa abrem a possibilidade de pensarmos que tais artistas articulam seus modos de existência com processos de criação desestabilizando um sistema de mundo no qual a opressão de gênero é racializada e oriunda de uma lógica colonial, capitalista e heterosexista. Seus corpos - e suas performances - parecem nos lembrar que não temos o direito de renunciar a existência e que a sobrevivência não basta.

\section{Performance e feminismos}

Este artigo está orientado pelo uso de uma epistemologia feminista que busca visibilizar os lugares de fala, e logo os vieses e posicionalidades que a orientam, com o intuito de trazer para o debate as limitações de uma perspectiva corporal e concretamente localizada, os possíveis preconceitos e posições de privilégio que ocupo ao me colocar como alguém que fala do trabalho de outras pessoas. É preciso que eu me posicione enquanto sujeito de fala e que deixe evidente que as reflexões que aqui farei são partes de um saber localizado, que não se pretende universal nem esgotado. Certas categorias sociais naturalizadas oriundas de um sistema colonial/moderno de gênero (Lugones, 2001) que operam sobre o meu corpo e me identificam como mulher, cisgênero, branca, brasileira, de classe média, etc., são categorias limitantes que não me definem mas que me marcam, localizam a posição de enunciação de meu discurso e deixam rastros em minha trajetória como acadêmica e como artista, ou, como tenho preferido, como atuadora². A intenção, ao evidenciar o lugar de enunciação deste discurso, é buscar romper com uma objetividade científica desincorporada (Haraway, 2005), pois tal objetividade é herança do um sistema de mundo que forja o sujeito cartesiano abstrato, concede-lhe privilégios e posições de poder que o desimplicam de suas análises. Tal sujeito é aquele que olha sem ser visto. A crítica à desincorporação dos sujeitos que detêm o poder de criar significados dominantes vem sendo operada via dispositivos artísticos como, por exemplo, performances a partir das quais as pessoas desenvolvem as ações se valendo de seus próprios corpos como mote e suporte da criação.

2 As categorias sociais de identidade são ferramentas do sistema colonial/moderno que atendem a lógica da biopolítica e do capitalismo. Estas não deixam de ser importantes para as disputas políticas por direitos mas ao mesmo tempo é preciso entender que tais categorias são naturalizações - e ficções - altamente violentas e arbitrárias já que a afirmação da existência de gênero e de diferença sexual, para ficarmos com dois exemplos, é altamente problemática porque baseada em discursos médico-jurídicos heternormativos que pressupõem que existam somente dois gêneros opostos, masculino e feminino, e que as anatomias corporais são passíveis de dividirem os corpos em dois grandes grupos, também opostos. 
No livro El Cuerpo del Artista Tracey Warr e Amelia Jones trazem a tona algumas articulações entre a performance e os feminismos. Warr pondera que os pensamentos acerca do o quê é o corpo, problematizações sobre como este é descrito e concebido estão presentes tanto nas teorias feministas quanto na arte (Warr, 2006). Seguindo a Warr podemos pensar que se o corpo é o lugar onde o domínio público se encontra com o privado, onde o social é negociado e se produz, o corpo também transborda sentidos ${ }^{3}$. De forma que pensar a performance em articulação com o campo de saber constituído pelos feminismos me parece estratégico uma vez que uma das grandes contribuições dos discursos críticos feministas é reconhecer que vidas vivem em corpos. Pode parecer ingênuo e cansativo repeti-lo mas, considerando a tradição metafísica desencarnada que encampa o pensamento ocidental, capitalista e colonial moderno sobre gênero, raça e sexualidade, repetiremos. Infelizmente as vidas não valem o mesmo simplesmente porque são vividas em corpos que o sistema moderno/colonial de gênero com sua lógica categórica dicotômica e hierárquica tratou de relegar a condições próximas ao "não-humano" (Lugones, 2001, p.105).

Não por acaso o investimento na materialidade do corpo, com suas características particulares e marcas sociais, segue sendo uma tendência artística utilizada principalmente, mas não exclusivamente, por corpos não-hegemônicos ou não-normativos no que tange o sistema moderno/colonial de gênero. Amelia Jones, em outra importante publicação de sua autoria sobre performance, Body Art - Performing the Subject, sinaliza que o uso do corpo como objeto artístico foi tremendamente questionado nos anos de 1970 e 1980 tanto por correntes críticas de arte afiliadas ao pensamento formalista e greenberiano quanto por críticas feministas como Mary Kelly e Griselda Pollock. Neste livro a autora argumenta que por um lado alguns críticos de arte contestavam a body art tanto por fazer um uso rudimentar das ferramentas artísticas tradicionais quanto por não utilizar de estratégias da vanguarda, como o efeito de distanciamento de Brecht ao qual na visão de Jones a body art se opõe, e por outro certas críticas feministas repudiavam o uso do corpo próprio em performance, principalmente por mulheres, por acreditar que devido à objetificação do corpo da mulher na sociedade capitalista, colonial e patriarcal, a obra seria automaticamente alvo do fetiche masculino, interditando assim qualquer reflexão crítica veiculada por ela.

Passadas mais de quatro décadas de ascensão e rechaço da body art, e de permanentes revisões das teorias críticas do feminismo, importa sim refletir sobre certos usos do próprio corpo em performances contemporâneas atentando para teorias feministas que levam em consideração a interseccionalidade dos eixos de diferenciação social, e que consideram que o sujeito político "mulher" não abarca as problemáticas que travamos cotidianamente como sujeitos não-hegemônicos.

O feminismo pode ser entendido não só como um movimento social e político heterogêneo, mas como um conjunto de discursos críticos dos mais significativos surgidos no século XX. Não que as teorias/movimentos feministas e os movimentos de mulheres tenham surgido somente no século passado. Vale ressaltar que as

3 Jones propõe que o corpo "es el lugar donde el dominio público coincide con el privado, donde lo social se negocia, se produce y adquiere sentido." (Jones, 2006, p.20). Reconhecendo a importância da produção acadêmica de Jones para a história da arte resolvi aqui desdobrar a proposição acima citada pois, se o corpo é o local onde o social se negocia seria interessante pensarmos que é também o local onde transbordam sentidos. 
perspectivas feministas que orientam minha vida e minhas práticas artísticas estão mais próximas dos feminismos interseccionais, descoloniais e transfeministas do que de outras vertentes. Considero que o corpo, o sexo, o pertencimento de gênero e a sexualidade não são dimensões acabadas nem dadas de antemão. São, a meu ver, dimensões plásticas, em construção e em permanente negociação. Ao designar tais dimensões como plásticas não quero dizer que estas não deixem marcas nos corpos, e sim que podem ser vivenciadas e manipuladas de formas distintas por cada sujeito.

Uma boa maneira de começar a visibilizar as possíveis relações entre os feminismos e a performance é apontada pela artista e investigadora mexicana Monica Mayer no artigo Un breve testimonio sobre los ires y venires del arte feminista en México durante la última década del siglo XX y la primera del XXI quando ela diz que a performance quer borrar a linha entre a arte e a vida, e os feminismos querem borrar a linha entre o pessoal e o político (Mayer, 2009). No entanto, meu interesse não passa por designar ou categorizar tais performers ou suas performances como feministas pois mesmo entendendo que para muitas pesquisadoras exista algo como uma "arte feminista", tal expressão me parece equivocada correndo o risco de um reducionismo complexo. Este artigo visa tão somente explicitar as relações de mão dupla que há muito tempo ocorrem entre o campo da performance e de algumas teorias e movimentos feministas.

Segundo Jones é importante evitarmos articulações entre os feminismos e a performance (ou a body art) que os coloquem como causa-efeito um do outro. Em seus estudos a autora opera uma análise pós-estruturalista, fenomenológica e feminista para desvelar os mecanismos pelos quais mesmo a crítica e história de arte pós-modernas foram esvaziadas das "políticas corporais", e de questões de subjetividade e identidade, ao passo em que devido a uma instrumentalidade técnica as críticas pós-modernas vem colocando ênfase em estratégias de produção como a apropriação, a alegoria, e a crítica institucional (Jones, 1998). Sua intenção tem sido mostrar os dispositivos através dos quais a body art foi renegada pela história da arte e inclusive desvalorizada por parte de importantes críticas feministas.

Seus pontos centrais de análise são a descentralização do sujeito cartesiano que a performance e a body art operavam, a intersubjetividade que se dá entre artista e público quando o corpo da/o/x performer é o objeto artístico da performance, a contingência de todo o significado e da noção de alteridade, a mudança no regime de recepção da obra de arte e o abalo do modelo kantiano de julgamento estético desinteressado, conseguido através de critérios objetivos. Em um denso exame de todos estes pontos Jones indica que as críticas que a body art e a performance sofreram eram desincorporadas e enviesadas pela monocultura de modelos teóricos de análise do self e da alteridade baseados na visão. Essa é a crítica que a autora faz às análises feministas que rechaçavam o uso do corpo em obras artísticas que fossem feitas por mulheres: a preponderância de um regime visual nos modelos teóricos de análise que vêm desde a teoria cartesiana e que permanece na psicanálise através de teorias lacanianas da constituição do self4. Através deste tipo de análise feminista, simplesmente pelo fato do corpo estar presente e em primeiro plano, a body art foi

4 Como exemplo Jones cita e problematiza as análises de Mary Kelly e Griselda Pollock sobre o uso do corpo na body art. 
rejeitada como sendo essencialista, pois refém da anatomia, e reacionária ${ }^{5}$.

Segundo Jones também uma noção problemática de presença acompanhava os discursos de alguns praticantes, de críticos e de espectadores de performance e body art, dando margem para afirmações de que a performance possuiria um poder especial de veicular a presença do artista de forma direta e não mediada. Tal noção de presença de forma direta e não mediada, é altamente questionada por Jones em outros artigos, principalmente acerca da mercantilização atual da performance cujo diferencial com relação a outras formas artísticas seria um adicional de presença.

Para a autora a performance e a body art propõe um engajamento intersubjetivo na relação com o público, evidenciando e contribuindo para a descentralização e o deslocamento do sujeito cartesiano. Seguindo as reflexões de Jones podemos pensar que, trabalhos autônomos de performers mulheres em que estas utilizam seu próprio corpo nu possuem o potencial de desafiar a mirada escopofílica, recusando o processo fetichizante e ativando um modo de produção e de recepção da obra que é altamente intersubjetivo (Jones, 1998). Seu posicionamento é que as artes do corpo quando insistem na intersubjetividade teriam a potencia de expor o circuito do desejo que informa a produção e a recepção de significados.

Através de alguns estudos de caso em suas análises, como Yayoi Kusama, Ana Mendieta e Carolee Scheenmann, a autora mostra-se bastante consciente de como a interseccionalidade opera na construção, produção e recepção de performances em que a/o/x performer é um corpo não-hegemônico, não-normativo ou não-binário. Por exemplo, ao se debruçar sobre o trabalho de Kusama, Jones tem consciência que sobre o corpo da performer operam tanto o sexismo quanto o racismo e a xenofobia pois afirma que o gesto da artista "entrelaça tropos de gênero, sexualidade e etnicidade" (Jones, 1998, p.8). Os eixos de diferenciação social relativos a gênero, raça e etnia se articulam de tal forma que não podemos entender Kusama somente como mulher ou somente como sujeito asiático.

Para entendermos melhor esse exemplo utilizado por Jones precisamos recorrer aos feminismos que consideram necessário interseccionar gênero com outras características implicadas nos processos de subjetivação social. Nesses casos o gênero se articula e se combina com outros eixos de análise da opressão e das diferenças e desigualdades sociais. Os feminismos interseccionais orientados em grande medida pela teoria da interseccionalidade cunhada por Kimberlé Crenshaw, mulher americana negra, buscam demonstrar que as categorias identitárias não existem de forma isolada nem a priori. Nesse sentido o sujeito não pode ser entendido como uma simples soma de diferenças e particularidades como na fórmula gênero + nacionalidade + etnia + classe + etc. É preciso compreender as articulações e agenciamentos entre as distintas dimensões da identidade.

Seguindo essa lógica não podemos pensar o gênero como uma categoria pura, muito menos como uma categoria isolada de outros elementos que compõe nossa identidade e operam em nossa subjetividade. Ao analisar a linha construcionista de abordagem interseccional Adriana Piscitelli afirma que as categorias de identidade

5 Uma importante fonte que busca reforçar que as performances feitas durante os 1960 e 1970 não eram somente de cunho essencialista, apesar de se valerem do próprio corpo como objeto artístico, é o catálogo da exposição \#2 re.act feminism - a performing archive que, com relação a isto, cita o trabalho da brasileira Letícia Parente, entre muitas outras performers, como sendo desafiadores de categorias identitárias puras ou essencialistas. 
que incidem sobre os processos de subjetivação são categorias articuladas: "As categorias de diferenciação não são idênticas entre si, mas existem em relações, íntimas, recíprocas e contraditórias. Nas encruzilhadas dessas contradições é possível encontrar estratégias para a mudança" (Piscitelli, 2008, p. 268). A experiência de gênero de cada pessoa está diretamente relacionada com seu pertencimento e posicionamento de raça, de classe, de nacionalidade, etc. Logo, a importância das experiências vividas de cada pessoa será sempre única e deverá ser levada em consideração. Para a interseccionalidade o contexto tem papel determinante, portanto presta-se atenção a sempre instável imbricação entre privilégios e opressões. Análises que não levem a interseccionalidade em conta não conseguirão abarcar os modos particulares de opressão - nem as possibilidades de agência e resistência - dos sujeitos envolvidos.

Assim, a estratégia artística escolhida por Kusama é, então, exacerbar "as diferenças" que lhe constituem. A isto Jones chama de dupla alteridade (Jones, 1998). Diversos artistas trabalham com esta estratégia, como é o caso do coletivo transnacional La Pocha Nostra ${ }^{6}$ no qual os/as/xs performers buscam, através do que chamam de antropologia inversa, empurrar a cultura dominante para as margens performando identidades múltiplas, híbridas e fragmentadas enquanto exageram ou parodiam aspectos de suas próprias identidades para com isso expor a contingência relativa ao que consideramos semelhante e/ou diferente.

O gesto de revelar a particularidade do próprio corpo é um importante gesto e uma poderosa estratégia usada também em teorias e epistemologias feministas para desafiar a objetividade científica desincorporada e os discursos totalizadores. No caso da performance, tal gesto desafia a fácil posição voyeurística do espectador ou do sujeito neutro, abstrato, não corporificado. A relevância deste gesto é aguda pois implica que artista e espectador são ambos responsáveis pela produção de sentido relativo aquilo que está sendo mostrado. É importante reter que para Jones o corpo particularizado teria o potencial de evidenciar que o/a/x artista é um corpo/ self necessariamente implicado na obra de arte mas, sobretudo, evidencia a obra de arte como um ato social e situado. Além disso, particularizar o corpo é uma estratégia para revelar a contingência da alteridade, do corpo/self do artista em relação ao corpo/self dos espectadores da obra. Quando ambos são marcados como contingentes o espectador não pode mais convocar um desinteresse de seu julgamento estético em relação à obra de arte.

Como iremos tratar de trabalhos de artistas brasileirxs em articulação com proposições críticas feministas é importante atentarmos para o contexto brasileiro no qual infelizmente a relevância do campo de saber constituído pelas teorias feministas ainda é pequena em setores como a crítica, a pedagogia e a criação em artes cênicas. Segundo a Heloisa Buarque de Hollanda (2001), a grande resistência de identificação com o feminismo por parte dos mais distintos grupos de mulheres no Brasil se deve a forma pela qual foi construído o movimento feminista dominante no país e às pautas que abraçou. Os movimentos feministas organizados começam a surgir aqui durante a década de 1970, no período ápice da ditadura militar (1964-1985). Esta conjuntura 
fez com que o feminismo brasileiro se vinculasse a grupos de esquerda e, de forma problemática, a Igreja Católica e seus setores mais progressistas, aqueles que eram opositores do regime militar. Aqui a agenda prioritária do movimento feminista organizado não se ateve a pautas tradicionais específicas relativas aos direitos das mulheres. Priorizou, por suas alianças, tratar de direitos civis e liberdade política e sócia, a enfrentar temas centrais como a igualdade salarial e de oportunidades, direito ao divórcio, ao aborto, a liberdade sexual, violência doméstica e feminicídio. O escopo de reivindicações ao que se atrelou o pensamento feminista no Brasil determinou em grande parte o desinteresse pelo conjunto de discursos críticos feministas apesar de tais discursos terem avançando enormemente em suas proposições nos últimos trinta anos.

Além disso, é preciso termos em mente que o feminismo que surge na chamada segunda onda (anos 1960 e 1970) é criticado por algumas autoras feministas como "feminismo branco" (Piscitelli, 2008, p.266). Essa rotulação crítica deve ser levada em conta uma vez que os movimentos e conceitos de interseccionalidade e articulação das diferenças, entre outros surgidos na chamada terceira onda feminista, são criados justamente para apontar criticamente a universalização do sujeito mulher pelas feministas brancas, bem como a universalização dos modos "corretos" de resistência que, consequentemente, promoviam um apagamento das particularidades e especificidades de cada sujeito e das múltiplas formas de opressão e ação.

Já estamos em outro momento no que tange aos pensamentos feministas no Brasil, apesar de no plano material não termos avançado significativamente na maioria das tradicionais pautas centrais elencadas acima. O interessante dos ventos feministas que sopram atualmente em diversos contextos nacionais e internacionais é o entendimento da interseccionalidade das opressões e da articulação das diferenças. Esses ventos foram impulsionados, é preciso fazer justiça, por inúmeros grupos de mulheres que não eram reconhecidas pelos movimentos feministas heterocentrados e dominantes, compostos majoritariamente por mulheres brancas de classe média ou elite.

Isso levou também a buscas por outras formas de se definir, como é o caso dos movimentos transfeministas. De acordo com Miriam Solá o termo transfeminismo surge nas Jornadas Feministas de Córdoba ocorridas em 2000. É oriundo de uma necessidade política de considerar a multiplicidade do sujeito feminista. Além disso, Solá aponta que a relativização das identidades que o termo queer propõe poderia levar a um ocultamento da assimetria entre homens e mulheres. Trata-se de um reconhecimento de que a crítica ao binarismo de gênero operada pelos estudos queer poderia invisibilizar as desigualdades estruturais de gênero. Assim, o termo busca manter um vínculo com as lutas feministas que nos precederam e evita que esqueçamos que ainda existem diferentes posições de poder entre homens e mulheres na sociedade (Solá, 2014). É devido a este alargamento de horizontes, da vontade de liberar o feminismo das políticas identitárias, do reconhecimento e das alianças com os "sujeitos efeminados da história" (Preciado, 2014, n.p.), que podemos e devemos incluir trabalhos como o de Pêdra Costa numa cartografia que visa relacionar performances e afetos-efeitos feministas. A expressão usada por Paul B. Preciado não se dirige necessariamente a pessoas homossexuais ou transexuais. No contexto em que 
foi usada refere-se a todos os sujeitos que passam por processos de subalternização, precarização e subordinação devido a características biológicas’, raciais, étnicas, sociais, culturais e políticas.

A importância da inserção do amplo conjunto de discursos críticos feministas no campo das artes passa também por uma falta de crença na lei e no Estado como os únicos capazes de proporcionar transformações sociais, pois já entendemos que as mudanças devem ocorrer primeiro e fundamentalmente no plano da subjetividade, onde podemos "dar lugar aos processos de singularização, de criação existencial, movidos pelo vento dos acontecimentos" (Rolnik, 1996, p.3). É aqui que se firma a importância da arte e da produção de imagens-outras. É aqui que se juntam a performance e as resistências feministas na arte da vida.

Antes de adentrar os trabalhos Merci Beaucoup, Blanco!, gordura trans \#3/gordura localizada \#1 e Solange, tô aberta! uma dúvida quase paralisante: como tratar de cartografar e refletir sobre essas performances sendo que só em uma delas eu estive presente? Me apoio novamente em Jones para quem os documentos de performance são tão validos, tão contingentes e tão subjetivos quanto à análise de quem viu a obra ao vivo. No artigo The artist is presente (2011), Jones argumenta que as problemáticas noções de presença veiculadas pelos estudos da performance e da autenticidade da análise de quem viu a performance ao vivo são heranças do discurso modernista. Certamente quem vê uma performance ao vivo terá memórias corporificadas da obra, mais tais memórias não deixam de ser também mediadas e subjetivas. Ver uma performance ao vivo não garante um acesso mais profundo ou verdadeiro a esta do que tentar apreender algo de sua estrutura e se deixar afetar por sua força via documentos e registros. Por mais paradoxal que seja a performance, mesmo sendo efêmera, sempre dependeu de documentos. Toda descrição textual, oral, ou audiovisual acaba fazendo parte da performance pois são reiterações que fazem o trabalho circular como discurso. Obviamente a análise de uma performance que não vi ao vivo será limitada mas isso não impede que eu fale sobre ela pois os registros são algo mais que suplementos, são aquilo que produzem o que supostamente estão a complementar. Como estas performances já ocorreram em diversos contextos e com variações internas minha escolha não busca avalia-las criticamente e sim fazer uma descrição analítica da matriz performática de cada um desses trabalhos com o objetivo de demonstrar porque importa incluí-los numa cartografia de trabalhos com efeitos e afetos transfeministas.

\section{Oferendas performativas}

Merci Beaucoup, Blanco! se vale de uma estratégia artística em que a materialidade e a economia dos elementos escolhidos dão o tom da performance. Michelle Mattiuzzi, também conhecida como Musa, mulher negra nascida em São Paulo, está nua. Usando saltos altos e sentada sob um banquinho de rodas, gira em torno de si

7 Para acompanhar o pensamento de Preciado talvez fosse mais adequado substituir "características biológicas" por características "anatômico-políticas" (Preciado, 2002, p.134) para fazer evidente o caráter político de todo discurso médico-científico. E no que diz respeito às complexas noções de raça e etnia é interessante acompanhar o pensamento de Kabengele Munanga (2003) proferido no $3^{\circ}$ Seminário Nacional Relações Raciais e Educação e disponível em: http://www.geledes. org.br/wp-content/uploads/2014/04/Uma-abordagem-conceitual-das-nocoes-de-raca-racismo-dentidade-e-etnia.pdf 
mesma algumas vezes. Durante as voltas que dá sua cabeça encontra-se geralmente inclinada para baixo, remetendo a brincadeiras de criança e com ares de certa timidez. Após um tempo para, dá as costas para o público e utilizando um pincel começa a pintar seu corpo de tinta branca. Começa pelas pernas. Depois, abandona o pincel e começa a valer-se de suas negras mãos para pegar a tinta branca. Vez ou outra para e cavalga no banco, aludindo a atos sexuais. Vez ou outra sorri. Vez ou outra toca os seios e o corpo de forma sensual e provocativa. Vez ou outra se abraça com ternura. Ao terminar de passar a tinta branca por quase toda a extensão de seu corpo, levanta-se e sobe no banquinho. Mostra-se de pé e roda, como aquelas bonecas antigas que giravam aprisionadas numa caixinha em miniatura. A tinta branca vai escorrendo pelo corpo.

gordura trans \#3/ gordura localizada \#1, também faz um uso certeiro das especificidades políticas da materialidade de três elementos. $O$ primeiro, o corpo de Miro Spinelli, branco, cabelo raspado, nu, gordo, com seios e barba expressivos. $O$ segundo elemento é o que despejará sobre si. De pé, verte, começando pelo topo da cabeça, uma a uma, cinco garrafas de azeite de dendê. E deixa escorrer. Passa a mão nos olhos, tirando um pouco do excesso. Após esvaziar as garrafas se senta e olha a plateia. A ação ocorre no espaço público, que considero o terceiro componente fundamental do trabalho' . $^{\circ}$

Solange, tô aberta! É acionada por Pêdra Costa que se define como sendo de "descendências mescladas raivosas, nascida e vivida a infância pobre em Nova Iguaçu, gay afeminada, bicha-trans-lésbica, trans em trânsito" (Costa, 2016) ${ }^{8}$. Possui um fofo coração vermelho tatuado na bunda. Veste: calcinha-enfiada-na-bunda. Opcionalmente veste ou alterna com: meia calça arrastão, salto alto e peruca. Microfone em mãos, ao som de uma batida de funk anuncia logo na primeira sequencia de graves que atingem o corpo do público "eu vou fazer uma orgia com Freud, Jung e Lacan"9 enquanto sobe, desce, empina, rebola, interage com o público, manda beijo, alisa, agarra, sobe, desce, empina e rebola. Seria um erro pensarmos que Pêdra está usando de travestismo teatral ou caricato, não está: "sou uma dama de pau, passiva-diva e tal, vagabunda, peituda, feminina e sensual, mulher paraguaia, muita gente até critica..." ${ }^{10}$. Não é um show de drag, a maquiagem não é perfeita, os pelos estão presentes. As músicas seguem com letras que versam sobre sexualidade, universo queer e homossexual, e sobre "identidades perturbadas, questões subversivas, poderes alterados, discursos desafiados, comportamento itinerante, gesto temporário." 11

\section{Ocupar o corpo-encruzilhada}

Em Merci Beaucoup, Blanco! o corpo de Mattiuzzi é, como ela mesma dizia durante uma das apresentações, o seu protesto. Estaria Mattiuzzi falando de embranquecimento, racismo e opressão baseada na raça ou estaria ela falando da opressão cruzada por ser negra e por ser mulher numa sociedade com um passado colonial

8 Auto definição feita por Pêdra em entrevista realizada por email.

9 Trecho de Dama de Pau: https://soundcloud.com/solangetoaberta/sta-dama-de-pau

10 Trecho de Macho Transtornado: https://soundcloud.com/solangetoaberta/sta-macho-transtornado 
que se atualiza em incessantes ondas? Em um registro em vídeo de uma das vezes em que realizou esta mesma performance Mattiuzzi está usando uma máscara de ferro facial, como aquela vista na figura de Eyin, mulher negra escravizada, conhecida popularmente como "Escrava Anastácia", e cultuada no Brasil e na África. Narrativas em torno dessa importante figura, dizem que ela foi obrigada a usar tal instrumento de suplício, que era retirado somente para comer, pois se negou a ter relações sexuais com um senhor de escravos. Não é "só" o racismo que esmaga e violenta a performer, é um racismo articulado a sexismo e misoginia, ao ódio e desprezo pelas mulheres e por tudo que é considerado feminino e que em várias medidas atinge o corpo das mulheres negras de uma forma particular que implica ainda em exotizar a sexualidade destas.

Refletindo especificamente sobre esta performance, Mattiuzzi comenta: "como eu resolvi pensar meu corpo enquanto matéria para a construção de linguagem artística, então não tem como eu esquecer todos os estereótipos que cabem a mim" (Mattiuzzi, 2013) $^{12}$. Seu processo artístico também é muito permeado pela troca intersubjetiva que se dá com quem vê a obra, com provocações de amigos ou público. Diz se incomodar muito pelo que ela mesma afirma ser uma "dualidade cartesiana" (Mattiuzzi, 2013) inerente ao corpo negro, que é ou exotizado ou marginalizado, e que encontrou no uso da nudez uma forma de provocar essa dualidade: "eu preciso questionar quem eu sou, senão eu não existo" (Mattiuzzi, 2013). Sua performance nos impele a refletir sobre nossos atos cotidianos e nos coloca frente a frente com o racismo misógino estruturante de nossa sociedade.

gordura trans \#3... atravessa meu corpo pela afirmação pública do corpo de Spinelli. Sua performance é um tapa na cara da gordofobia, da transfobia e da misoginia, simultaneamente. Não se trata somente de um corpo gordo, nem somente de um corpo trans, nem de um corpo de mulher, nem de um corpo de homem. Ali estão os seios, que nos remetem a um corpo considerado feminino pelos discursos médico-jurídicos. ${ }^{13} \mathrm{E}$ no fundo, na lógica heteropatriarcal sempre vigente um corpo de mulher não deveria nem estar ali, no espaço público. Muito menos nua. Muito menos quando também se tem barba. E muito, muito menos quando você é, ou está, gorda. Ou gordo. Sendo ou estando gorde, Spinelli, como afirma em seu site, tomou a decisão de não mais se cobrir. Em suas próprias palavras vale-se de "catalisadores simples para fazer brotar nossos desejos e pisotear junto com a gordura vegetal que escorreu a culpa que carregamos junto com o peso da nossa massa corporal" (Spinelli, 2014, n.p.). Nesta passagem x performer está se referindo a outra performance da série Gordura Trans, mas creio que vale para pensar gordura trans \#3... Sua ação nos revela em nossas tentativas de alcançar um padrão estético normativo, seja de gênero ou de ideal de beleza. Em suas reflexões críticas Spinelli mostra que para nossa sociedade, em geral, "o corpo gordo é, para todos os efeitos, um corpo indesejável. Está categoricamente instituído que desejar um corpo gordo para si ou desejar eroticamente

12 As citações de Mattiuzzi, nesta página, foram retiradas da seguinte fonte: https://www.youtube.com/watch?v=-IYnXBt8ZaE

13 É importante notar que tanto Pêdra quanto Miro tem posicionamentos semelhantes quanto aos seus pertencimentos de gênero. São pessoas que não se identificam com o espectro binário de gênero. Como apontado no início do texto a ideia de que só existem dois sexos, que seriam opostos, de onde derivariam dois gêneros, também opostos, sendo que o homem é o masculino e a mulher o feminino é altamente contestada por estudos feministas, interseccionais e trans. De acordo com Conceição Nogueira não se deve nem mesmo considerar o gênero como um atributo individual pois que "ele [o gênero] não existe nas pessoas e sim nas relações sociais" (Nogueira, 2013, p. 228). 
o corpo gordo de outro é uma espécie de fetiche patológico"14. Para mim o que fica de sua performance é um convite a que deixemos escorrer nossas culpas e nossos medos, diversos, de desejar.

A performance Solange, tô aberta! (STA!) me interessa particularmente por ser uma performance em que a implicação do corpo do público é altamente perceptível. ${ }^{15}$ Apesar de ser considerada em alguns contextos como uma performance musical, por ter um formato de show, proponho pensar STA! como uma performance que faz uso do funk como estratégia artística de interpelação participativa do público. A música é sim um elemento fundamental de sua ação mas quem ativa a música é Pêdra, com seu corpo e sua história de vida. Seria difícil que outros corpos (penso, por exemplo, num corpo normativo de um homem cisgênero, gay ou hetero, ou mesmo uma mulher com corpo dentro do padrão estético normativo) causassem o mesmo impacto que a performance STA! causa quando é acionada pelo corpo de Pêdra que afirma que a performance é uma "comemoração dos corpos abjetos, das violências e solidões sofridas" (Costa, 2014, n.p.) ${ }^{16}$. Seu interesse por usar o funk como linguagem também tem a ver com a força que o funk proibidão cantado por funkeiras, que afirmam seus desejos e sexualidades, exerce como contra-discurso à lógica hegemônica heteronormativa que os silencia quando expressados por mulheres, ainda que às vezes o "capitalismo antropofágico" pareça destinar nichos específicos para tais expressões ${ }^{17}$. A força de uma performance de STA! vem de sua proposta de pensar "O corpo como uma festa política. Não mais o corpo controlado pelos desejos capitalistas e nem mais as identidades de gênero sob os discursos de controle"(Costa, 2014, n.p.).

Observamos nas obras citadas algumas "tendências dramatúrgicas da performance" que vem sendo sistematicamente analisadas por Fabião. Tanto "a aguda simplificação de materiais, formas e ideias num namoro evidente com o minimalismo" (Fabião, 2008, p. 239) que podemos ver claramente nos trabalhos de Miro e Michelle, quanto "o desinteresse em performar personagens fictícios e o interesse em explorar características próprias (etnia, nacionalidade, gênero, especificidades corporais), em exibir seu tipo ou estereótipo social" (Fabião, 2008, p. 239) tendência que podemos observar nos três trabalhos citados, uma vez que Solange não é uma personagem fictícia de Pêdra. Neste mesmo artigo a autora, que também é performer, afirma que a disposição de certos artistas de usar o corpo como mote e suporte da performance levaria ao questionamento do quê é o corpo.

Se o performer investiga a potência dramatúrgica do corpo é para disseminar reflexão e experimentação sobre a corporeidade do mundo, das relações, do pensamento [...]. Se o performer evidencia o corpo, é para tornar evidente o corpo mundo" (Fabião, 2008, p. 238).

A atenção ao que proponho pensarmos como corpo-encruzilhada permitirá ao

\footnotetext{
14 As citações que aparecem neste parágrafo foram retiradas de um texto de autoria de Miro Spinelli e podem ser consultadas no site citado na nota 9.

15 A performance STA! começou a ser desenvolvida em 2006, em parceria com Paulo Belzebictchy, que não faz mais parte do projeto. Aqui ao me referir sobre a STA! estarei levando em consideração o período desde que conheci a performance, em 2013 até a última apresentação de STA! no Brasil, em Salvador, na qual estive presente, em setembro de 2015 , no mesmo evento citado na nota 9.

16 Palavras de Pêdra Costa em entrevista para o site: http://comehdia.blogspot.com.br/2014/02/entrevista-com-solange-to-aberta.html

17 A ideia de capitalismo antropofágico surgiu de uma provocação crítica lançada por Buarque de Hollanda (2001) sobre a tão exaltada noção de subjetividade antropofágica brasileira. No sentido em que empreguei me refiro ao poder do capitalismo de se apropriar de tudo o que é "diferente" da lógica dominante, extraindo do diferente só o que lhe interessa, e não a diferença que poderia de fato desestabilizá-lo.
} 
performer desenvolver poéticas em que consiga trazer a tona às intersecções das opressões sofridas. Permitirá lançar reflexões sobre como as articulações entre os marcadores sociais operam de forma contingente e contextual. Basicamente o conceito de corpo-encruzilhada quer convocar a ideia do entrecruzamento dos eixos de diferenciação social (pertencimento de gênero, raça, classe, nacionalidade, sexualidade, religiosidade, etarismo, capacitismo, etc.) que marcam o corpo e o expõe a situações de opressão ou privilegio, dependendo do contexto e da forma como usamos/usam essas marcas. O corpo-encruzilhada também remete ao choque entre o fluxo de desejos, a necessidade de lhes dar passagem e construir paisagens para os processos de singularização versus o enrijecimento e embrutecimento causados pela camisa de força dos identitarismos, com suas normas, tradições e maneiras corretas de existir. O corpo-encruzilhada traz ainda a ideia de movimento, já que é na encruzilhada que os caminhos paralelos ou díspares se encontram. Por fim, me parece útil pra pensar a coexistência de contradições nas pessoas, contradições que são agidas e/ou sentidas no, pelo, através, com o corpo.

Em entrevista realizada por email, perguntei aos artistas questões que se relacionavam com os temas aqui tratados. Suas respostas foram elucidativas de vários pontos que aqui interessam. Tanto Miro quanto Pêdra disseram se relacionarem com estudos e leituras feministas, interseccionais, transfeministas, "queer-feministas com pautas não-brancas" (COSTA, 2016, n.p). Também ambos foram receptivos ao conceito de corpo-encruzilhada para pensarmos não só o que ocorre em todos os corpos como também para pensarmos o trabalho em performance. Sobre a ideia de corpo-encruzilhada Miro fez a seguinte articulação:

Pensando na performance e no que aconteceu com meu corpo enquanto ela acontecia, eu poderia dizer que o corpo vira uma encruzilhada entre ele próprio e o corpo do outro [...]. Durante a ação, sinto-me negociando naquele momento a minha própria existência (a existência do meu corpo) no espaço com aquelas pessoas, de forma muito direta. Ele talvez se torne uma encruzilhada, entre o olhar do outro e ele próprio que olha de volta. (Spinelli, 2016, n.p.).

O pensamento feminista sobre as diferenças, e sobre a articulação/interseccionalidade dos eixos de diferenciação social tem muito a contribuir para o campo das artes cênicas como um todo e especialmente para a pedagogia da criação em performance. Porque as diferenças existem nos corpos, pelos corpos, e em relação. Para todas as pessoas que trabalham com performance a atenção à materialidade de nossos próprios corpos nos ajuda a criarmos conscientes de como operam, contextualmente, os significados atribuídos a nossos corpos, podendo assim, desafiar alguns destes significados e problematizá-los. Ajuda a termos uma margem mínima de previsão sobre como tal ação, desempenhadas por este corpo específico, poderá ser percebida dentro do contexto em que será apresentada.

Tanto a performance quanto os feminismos, talvez mais especificamente que outros campos de saber, são terrenos de negociação e de disputa de significados. Segundo Fabião a performance pode ser pensada como a arte da negociação (Fabião, 2009). Para Adrian Heathfield a preocupação crítica da performance está relacionada a um desejo de "quebrar tradições da representação, para colocar o empírico em 
primeiro plano, para abrir diferentes tipos de compromisso com o significado, para estimular o público" (Heathfield, 2014, p.3). Também os feminismos contemporâneos travam uma luta pelo poder interpretativo. Mas essa não é, ou não deveria ser, uma luta por uma nova hegemonia, pela substituição de um conjunto de discursos totalizadores por outro. O que buscamos é que a produção de conhecimento seja feita através de uma objetividade corporificada, de saberes localizados e conhecimentos situados. Pois conhecemos os danos causados pelo sujeito cartesiano, não-corporificado, aquele que vê sem ser visto. O que se busca é a responsabilidade ética na geração do mundo e dos significados. Particularizar a visão é também tornar-se responsável por aquilo que se aprende a ver.

Entendendo a arte da performance como "uma arena de responsabilidade ética" (Bernstein, 2011, p.388) e como um meio para a "democracia radical" (Gómez-Peña, 2005) creio que o diálogo entre a performance e os feminismos - a utilização da interseccionalidade como metodologia de pesquisa e investigação em performance por exemplo - é indispensável pois é ela que permite caminharmos na fita de moebius entre a macro e a micropolítica (Rolnik, 1999), entre saber-se dentro de uma lógica identitária e saber-se devir, desejo, porosidade e fluidez. Saber-se marcada, mas também inacabada e inacabável.

\section{Referências}

BERNSTEIN, Ana. Marina Abramovich: do corpo do artista ao corpo do público. In: AZEVEDO, Carlito, SUSSEKIND, Flora e DIAS, Tania (Org.) Vozes Femininas: gêneros, mediações e práticas da escrita. Rio de Janeiro: 7 letras, 2001, p. 378-402.

BUARQUE DE HOLLANDA, Heloisa. O Estranho horizonte da crítica feminista no Brasil. In: AZEVEDO, Carlito, SUSSEKIND, Flora e DIAS, Tania (Org.) Vozes Femininas: gêneros, mediações e práticas da escrita. Rio de Janeiro: 7 letras, 2001, p.15-25.

FABIÃO, Eleonora. Performing Feminist Archives. A Research-In-Process on Latin America Performance Art. In: KNAUP, Bettina \& STAMMER, Beatrice (Org.) Re.act feminism \#2 - a performing archive. Londres: Verlag fur moderne Kunst Nunberg \& Live Art Development Agency, 2014, p. 29 - 36.

Teatro e Performance: poéticas e políticas na cena contemporânea. Sala Preta, São Paulo, v.8, p.235- 246, 2008.

COSTA, Pedrâ. pesquisa "outras/nossas histórias da performance e das artes do corpo" [mensagem pessoal]. Mensagem recebida por < camilabastosbacellar@gmail. com > 13 jan. 2016.

Entrevista com “Solange tô aberta". Comehdia Blogspot. 7 fev. 2014. Disponível em: http://comehdia.blogspot.com.br/2014/02/entrevista-com-solangeto-aberta.html Acesso em 20 set. 2016. 
GOMEZ PEÑA, Guillermo. Ethno-Techno Writings on Performance, Activism and Pedagogy. Nova lorque: Routledge, 2005.

HARAWAY, Donna. Saberes localizados: a questão da ciência para o feminismo e o privilégio da perspectiva parcial. Cadernos Pagu, Campinas, n. 5, p. 7-41, 2005.

HEATHFILED, Adrian. Alive: (AO) VIVO. Performatus, n.9, p.1-21, 2014.

JONES, Amelia. Body Art/Performing the Subject. Minneapolis: University of Minnesota Press, 1998.

JONES, Amelia e WARR, Tracey. El Cuerpo del Artista. Londres: Phaidon Press, 2006.

. The Artist is present: Artistic Re-enactments and the impossibility of presence. TDR/The Drama Review, Nova lorque, v. 55, n.1, p-16-45, 2011.

LUGONES. M. Hacia un feminismo descolonial. La manzana de la discordia. Cali: Universidad del Valle: 2011, v. 6. N. 2, p. 105 - 119.

MATTIUZZI, Michelle. pesquisa "outras/nossas histórias da performance e das artes do corpo" [mensagem pessoal]. Mensagem recebida por < camilabastosbacellar@gmail.com > 14 abr. e 30 set. 2016 .

MAYER, Monica. Un breve testimonio sobre los ires y venires del arte feminista en México durante la última década del siglo XX y la primera del XXI. Debate feminista, v. 40 , out. 2009, p.191-205.

MUNANGA, KABENGELE. Uma abordagem conceitual das noções de raça, racismo, identidade e etnia. Palestra proferida no 30 Seminário Nacional Relações Raciais e Educação, PENESB-RJ. Disponível em: http://www. geledes.org.br/wp-content/uploads/2014/04/Uma-abordagem-conceitual-das-nocoes-de-raca-racismo-dentidade-e-etnia.pdf < Acesso set 2016 >

PRECIADO, Beatriz. Manifiesto ContraSexual. Madrid: Editorial Opera Prima, 2002.

PISCITELLI, Adriana. Interseccionalidades, categorias de articulação e experiências de migrantes brasileiras. Sociedade e Cultura. V. 11, n. 2, p. 263-274, 2008.

PRECIADO, Paul B. Liberar o feminismo das políticas identitárias. Liberatión, França, mai. 2014,Trad. Silvio Pedrosa, Disponível em: http://uninomade.net/tenda/liberar-ofeminismo-das-politicas-identitarias/ Acesso em jan. 2016.

ROLNIK, Suely. Toxicômanos de identidade. Subjetividade em tempo de globalização. In: LINS, Daniel (Org.) Cultura e Subjetividade. Saberes Nômades. Campinas: Papirus, 
Molda-se uma alma contemporânea: o vazio pleno de Lygia Clark. In: The Experimental Exercise of Freedom: Lygia Clark, Gego, Mathias Goeritz, Hélio Oiticica and Mira Schendel, The Museum of Contemporary Art, Los Angeles, 1999. Disponível em: http://www.pucsp.br/nucleodesubjetividade/Textos/SUELY/ Molda.pdf Acesso em ago.2016.

SOLÁ, Miriam \& URKO, Elena. Transfeminismos. Epistemes, fricciones y flujos. Tafalla: Txalaparta, 2014

SPINELLI, Miro. pesquisa "outras/nossas histórias da performance e das artes do corpo" [mensagem pessoal]. Mensagem recebida por < camilabastosbacellar@agmail. com > 22 jan. 2016.

\section{Sites}

Solange, tô aberta!

https://vimeo.com/11001192

http://comehdia.blogspot.com.br/2014/02/entrevista-com-solange-to-aberta.html https://medium.com/revista-rosa-3/solange-to-aberta-a51c5bed42f2\#.k07jer5el https://soundcloud.com/solangetoaberta

Gordura Trans

http://gordura-trans.tumblr.com/

http://acoisatoda.com/2015/09/09/monstrxs-empoderadxs-no-desfazendo-genero/tamiris-spinelli-gordura-trans/

http://forum.lolesporte.com/viewtopic.php?f=8\&t=64028

Merci Beaucoup, Blanco!

http://musamattiuzzi.wix.com/musamattiuzzi

https://www.youtube.com/watch?v=-IYnXBt8ZaE

https://www.youtube.com/watch?v=Wm7Gt-noR3Q

Recebido em: 30/09/2016

Aprovado em: 02/11/2016 